\section{Europe nears compromise}

Brussels

Too tough for some, too lenient for others, the Commission of the European Economic Communities (EEC) was last week required to defend its proposals to limit car exhaust pollution. At the same time, its experts began a last minute search for a compromise to avert an otherwise inevitable deadlock when the ten environment ministers meet in Luxembourg on 28 June. The compromise could involve not only a possible redefinition of the troublesome mediumrange category of car (now set at 1.4-2.0 litres) but also different emission standards for cars fitted with three-way catalytic converters and those relying on lean-burn technology.

Reactions to the original proposals (see Nature 20 June, p.622) have been sharply divided among the member states. France, Italy and Belgium have joined the United Kingdom in dismissing the emission standards for medium-sized cars as too strict. But West Germany, followed by the Netherlands, Luxembourg and Denmark (which wants to see US-style uniformly strict controls applied to all categories of cars), is set on tougher controls. In addition, the Commission's proposals have reopened the debate on large cars ( 2 litres and over) that appeared

\section{Mount Wilson's end Washington}

No rescue plan has materialized to save the Mt Wilson 100-inch telescope, due to be shut down next week by its owner, the Carnegie Institution of Washington (CIW). Although discussions are continuing to find a "suitable operator" to take over the facility, it seems increasingly unlikely that one will be found. The several rescue groups that had been formed by interested astronomers, professional and amateur, have apparently failed to raise the several million dollars necessary to keep the telescope in operation.

Carnegie announced its intention to close the telescope a year ago, citing the increasing financial burden of running both Mt Wilson and its newer Las Campanas observatory in Chile. More recently, CIW revealed plans for shutting down the other astronomical facilities at Mt Wilson. The 60-inch reflector, now used for solar and stellar observations, will continue operating until 1 July 1986. The solar observatories will continue operating only until next October, but CIW is willing, until 1 July 1986, to continue administering salaries and other operational budgets provided by outside grants. In other words, CIW offers a nine-month lease to outside investigators who can find their own money.

Stephen Budiansky to have been settled in principle on 20 March. The figures put forward by the Commission are unacceptable to Belgium, France and the United Kingdom despite the fact that the use of the threeway converter in the case of large cars had been agreed in March.

The Commission's proposals have also been sharply criticized by an outside expert, Dr Michael P. Walsh, former deputy assistant administrator for the US Environmental Protection Agency's mobile source air pollution control. In two papers made public last week, he maintained that the Commission's proposals ignore a number of important factors. In particular, they do not take account of increased car sales which, given the long timetable for implementing the proposals, could mean "significantly more pollution both in the short and long term".

According to Walsh, by the time the entire fleet is converted to the new standards, nitrogen oxide and hydrocarbon emissions will be almost three times more than equivalent US levels and carbon monoxide almost two and a half times more. "If member states choose to implement more 'permissive' standards, these estimates", he says, "are optimistic."

A major part of the problem is the test cycle used to establish the amount of pollutant emitted. The European test cycle, says Walsh, takes little account of modern driving conditions. A new European test cycle is being run at present, on the basis of which the standards now to be agreed will be modified in a year or two. This, Walsh says, will only serve to complicate the matter of laying down US-equivalent standards now.

The European Commission has always insisted that it is impossible to apply the US cycle to European cars. But Walsh says that European studies have shown that US test procedures are a more faithful reflection of current urban driving conditions. $\mathrm{He}$ concedes that the European test is effective in simulating dense congested traffic conditions, but says it will not suffice for assessing limits for NOX and hydrocarbons (which are generated at high speeds and carried over long distances).

Walsh maintains that the Commission's proposals as they stand will cut NOX emissions by only 39 per cent by the year 2010, while $\mathrm{HC}$ and $\mathrm{CO}$ emissions will fall by 24.4 per cent and 22.8 per cent. On the other hand, if US equivalent standards in the range of 4.6 grams per test $\mathrm{HC}$ plus NOX, $16 \mathrm{~g} / \mathrm{t} \mathrm{CO}$ and $2.4 \mathrm{~g} / \mathrm{t}$ NOX were applied for medium and large cars, the actual reduction in pollution could be 66.7 per cent for $\mathrm{CO}, 75$ per cent for $\mathrm{HC}$ and 76.7 per cent for NOX.
In response, the Commission has produced a paper supporting its proposed standards, which it says will reduce all car exhaust emissions by 70 per cent in the case of large cars and 73 per cent for medium cars, compared with 67 per cent reduction reached in the United States. Emissions of NOX, which are a principle concern of EEC, would be reduced to a level only slightly above that in the United States (1.56 million tonnes each year in EEC, compared with 1.48 million tonnes in the United States) with a further reduction possible when new limits (perhaps $5 \mathrm{~g} / \mathrm{t}$ ) are introduced during the planned second phase for small cars under 1.4 litres, bringing EEC emissions down to 1.41 million tonnes.

Commission experts estimate further that if EEC ministers agree to introduce US-type speed limits of 55 m.p.h. (88 k.p.h.) as well, global NOX emissions from Community cars could fall to 15 per cent below US levels. But this suggestion has so far been blocked by West Germany, whose cars incidentally emit the greatest volume of NOX $(637,000$ tonnes in 1980) and which is under the greatest pressure to adopt tough controls on air pollution.

Anna Lubinska

\section{Verification in space \\ Los Alamos, New Mexico}

Donald Kerr, director of Los Alamos National Laboratory, is calling for the United States to give more attention to how it would detect and assess new hightechnology Soviet anti-missile defences in other words, a Soviet star wars system. Kerr says that "the possibility should be anticipated" that the United States and Soviet Union might reach agreement to limit star wars defences, and points out that the first requirement of any such agreement would be a means of verifying compliance. Conventional reconnaissance might not be adequate to assess the capabilities of a Soviet star wars system.

Despite the new technical challenges of such a monitoring system, Kerr says he is "moving in that direction". The testing of laser weapons might be detected by looking for atmospherically-scattered repetitive pulses of light, for example, and satellites might be interrogated with particle beams to see if they contained fissile material: the radiation emitted would provide information on the isotopes present.

Kerr plans to argue his case in Stockholm next month at a conference on space weapons and international security hosted by the Stockholm International Peace Research Institute. Los Alamos National Laboratory has long undertaken research into ballistic missile defence and claims to be well placed to develop means of verifying compliance with anti-ballistic missile or other future treaties limiting arms in space.

Tim Beardsley 